\title{
Precariedad social en México y Argentina: \\ tendencias, expresiones y trayectorias nacionales
}

\author{
María Cristina Bayón
}

A

partir de la exploración de las articulaciones entre trabajo, desempleo, pobreza y desigualdad, este artículo analiza, desde una perspectiva multidimensional y dinámica, las formas que adquiere la precariedad social en México y Argentina en el nuevo escenario económico. Sostiene que el debilitamiento de los mecanismos integradores centrados en el empleo, la marcada desigualdad de oportunidades y la creciente rigidización de la estructura social, evidencian tendencias muy excluyentes, con perfiles específicos en cada país. Luego de analizar las trayectorias nacionales y el potencial integrador alcanzado bajo el modelo de industrialización mediante sustitución de importaciones, examina el deterioro de las condiciones laborales y de vida en las últimas décadas. Finalmente, expone algunos de los dilemas y desafíos que plantea a la investigación y a las políticas públicas el tránsito hacia sociedades más equitativas, solidarias e incluyentes.

Instituto de Investigaciones Sociales, 


\section{I}

\section{Introducción}

El mercado de trabajo no sólo ha perdido su potencial integrador y de movilidad social, sino que para vastos $\mathrm{y}$ crecientes sectores sociales se ha transformado en uno de los principales mecanismos generadores de vulnerabilidad y exclusión social. El incremento de los niveles de desempleo, junto a la extensión de la inseguridad laboral y la desprotección social, no sólo muestra un progresivo debilitamiento de la relación entre crecimiento económico y empleo, sino que cuestiona seriamente las potencialidades del nuevo modelo económico tanto para absorber fuerza de trabajo como para reducir la pobreza y las desigualdades persistentes y crecientes.

La intencionalidad integradora, como señala Pérez Sainz (2003), no forma parte del proyecto globalizador, y el mercado laboral emerge con más fuerza que antaño en la configuración de dinámicas de desintegración social. A la par de la erosión de los anteriores mecanismos integradores, la ampliación de las disparidades en la distribución de oportunidades para acceder a las "ventajas" que ofrecen los procesos en marcha, revela que la estructura social se hace cada vez más rígida. Las condiciones iniciales pasan a desempeñar un papel más y más decisivo en el destino de los individuos y se penalizan fuertemente las situaciones de desventaja heredadas, en un contexto marcadamente adverso para los "perdedores" del nuevo juego social.

La asociación entre desigualdad en la distribución del ingreso y exclusión social está mediada por el funcionamiento de las instituciones sociales, económicas y políticas, que favorecen o coartan las oportunidades de una experiencia social compartida, clave en toda práctica de ciudadanía. ${ }^{1}$ En América Latina,

\footnotetext{
${ }^{1}$ Niveles de desigualdad similares pueden tener diferentes efectos en términos de exclusión social, dependiendo del grado en que las oportunidades de hacer y obtener cosas reflejen los niveles de ingreso (Barry, 1998). Así, cuando la calidad de los servicios públicos de salud y educación es uniforme y lo suficientemente alta como para que ellos sean utilizados por la amplia mayoría de la población, el ingreso individual resulta menos relevante. Según expresó T.H. Marshall en 1950 (véase Marshall, 1992), la extensión de los derechos sociales es un medio para eliminar las desigualdades ilegítimas — ligadas al origen social— que influyen en la distribución de las oportunidades.
}

los procesos de exclusión social se expresan precisamente en las condiciones de la incorporación de vastos sectores sociales, en sus patrones de integración (Faria, 1995), que dan lugar a una inclusión desfavorable (Sen, 2000), a una ciudadanía de segunda clase (Roberts, 2004). Las desventajas no derivan de "estar afuera", sino precisamente de la segmentación producida por las instituciones del Estado, es decir, de una inclusión diferenciada en el sistema social. Dicha segmentación, característica histórica de los "regímenes de bienestar" latinoamericanos, emerge con mayor crudeza ante el progresivo desmantelamiento y mercantilización de los servicios sociales, dando lugar a una dramática profundización de las distancias sociales en función no sólo del acceso a oportunidades — de empleo, educación, salud, vivienda- sino de la calidad de las oportunidades a las que se accede.

Los patrones y trayectorias de dicha incorporación adquieren matices particulares en contextos sociales diversos. El reconocimiento de la heterogeneidad de las estructuras sociales de los países latinoamericanos y de los distintos perfiles que las expectativas de bienestar y equidad pueden adquirir - conforme a los patrones de urbanización, estratificación social, tradiciones laborales y mecanismos de provisión de bienestarconstituye un punto de partida necesario para evitar diagnósticos simplistas y demasiado generales acerca de las formas que asume la precariedad social en el nuevo escenario económico. ${ }^{2}$ Es precisamente el carácter acumulativo de situaciones de desventaja (Paugam, 1995) relacionadas con la precariedad ocupacional y con otras dimensiones de la vida económica y social

\footnotetext{
${ }^{2}$ El concepto de precariedad social abarca tanto las condiciones de vida como las condiciones de trabajo y sus mutuas implicaciones. El concepto de precariedad de las condiciones de vida se refiere a niveles inadecuados de ingreso y su persistencia en el tiempo, y a sus efectos en la situación de vivienda, en la erosión de redes sociales, familiares y conyugales, etc. El concepto de precariedad de las condiciones de trabajo se refiere a la naturaleza y calidad del empleo y lo que significan en cuanto a niveles de satisfacción y perspectivas de movilidad laboral, aprendizaje, desarrollo personal y otras (véase Gallie y Paugam, 2002).
} 
(familia, ingresos, condiciones de vida y contactos sociales) lo que hace que ciertos grupos sean más vulnerables a procesos de exclusión social.

$\mathrm{Al}$ respecto, las experiencias de Argentina y México tienen particular relevancia. Ambos países presentaron importantes diferencias en cuanto a sus condiciones iniciales de desigualdad y pobreza a comienzos del decenio de 1990, a la importancia de las clases medias en su estructura social, a sus tradiciones laborales y niveles de protección social, a los mecanismos de ajuste del mercado de trabajo y a los modos de inserción en la economía internacional. Sin embargo, debido tanto al profundo y extendido deterioro del empleo y los niveles inéditos de pobreza y desigualdad exhibidos por Argentina en ese decenio - agudizados tras la crisis del 2001 - como a la persistencia y profundización de una estructura social altamente segmentada e inequitativa en México, ambas sociedades presentan hoy mayores similitudes que a inicios de la década en términos de inequidad distributiva. ${ }^{3}$

Este artículo examina, desde una perspectiva multidimensional y comparada, las principales tendencias y expresiones de deterioro social de los dos países señalados en la década de 1990, explorando las formas que adquirió la relación entre trabajo, desempleo, pobreza y desigualdad en uno y otro contexto. En la sección II se analizan tanto las dinámicas integradoras como las excluyentes de la estrategia de industrialización mediante sustitución de importaciones que imperó en ambos países — con ritmos e intensidades diversos- entre 1950 y 1980 . Al respecto se destaca que las disparidades del potencial integrador alcanzado en ese período constituyen un elemento clave para entender las dimensiones y profundidad del deterioro de las condiciones laborales y de vida resultantes de su desmantelamiento. En la sección III se destacan algunas dimensiones útiles para comprender las formas diferentes que pueden asumir las transformaciones del mercado de trabajo, donde se combinan elementos de diversa naturaleza como los patrones de inserción en la economía internacional, las tradiciones laborales y el modo en que éstas permean las concepciones y prácticas acerca de lo que se considera "trabajo" y desempleo, así como las expresiones que adquiere la relación entre empleo, desocupación, informalidad y pobreza en los dos países considerados. ${ }^{4}$ En la sección IV se explora la progresiva rigidización de la estructura social en dos dimensiones clave: la desigualdad en la distribución de oportunidades educativas y el debilitamiento de las oportunidades de movilidad social a través del empleo, particularmente para aquellos sectores que ingresan en los peldaños más bajos de la estructura ocupacional. Por último, las conclusiones contenidas en la sección V buscan destacar algunos de los principales dilemas y desafíos que plantea a la investigación y a las políticas públicas el tránsito hacia sociedades más equitativas, solidarias e incluyentes.

\footnotetext{
${ }^{3}$ Durante la primera mitad del decenio de 1990, Argentina se ubicó, según su coeficiente de Gini, entre los países de la región con niveles medios de desigualdad en la distribución del ingreso. Hacia fines de la década pasó a formar parte (junto a la mayoría de los países latinoamericanos) de aquellos con alta desigualdad, y en 2002 se encontraba (junto a Brasil y Honduras) entre los países con más desigualdad de la región. México se mantuvo en el grupo de países de alta desigualdad entre 1990 y 1999 , y pasó al de desigualdad media en 2002 (CEPAL, 2004a). El descenso de la concentración del ingreso experimentada por México en el último período debe ser analizada con cautela. No sólo resulta llamativa en un contexto económico adverso —en que la producción se estancó y el ingreso por habitante se redujo $2,6 \%$ entre 2000 y 2002—, sino que además hubo modificaciones en el diseño muestral (tamaño y distribución
}

de la muestra) y cambios en el cuestionario de la Encuesta de Ingresos y Gastos 2002, lo que dificulta su comparación con la encuesta del 2000 (véase CEPAL, 2003, recuadro I.4).

${ }^{4}$ Cabe destacar que los datos disponibles para el análisis de ambos países abarcan hasta 2002 y corresponden a un período de bajo desempeño económico en México y de plena crisis en Argentina. Esto afecta particularmente el comportamiento de algunos de los problemas aquí abordados, sobre todo en la sección III, apartado 2 , relativo a la informalidad y la desprotección, donde se explora la relación entre precariedad laboral, desempleo y pobreza. La ausencia de datos comparables más actualizados al momento de escribir este artículo limitó la posibilidad de indagar más a fondo en las tendencias de estas variables en Argentina y México, más allá de las etapas del ciclo económico. 


\section{Estrategias de desarrollo, empleo e integración social: expectativas incumplidas, promesas olvidadas}

La desigualdad y la pobreza no son ciertamente fenómenos nuevos en América Latina. Sin embargo, si evaluamos el impacto de las diversas estrategias o modelos de desarrollo sobre las estructuras sociales de los países de la región, se advierte que ellos han tenido implicaciones dispares en términos de su potencial integrador.

Hasta la década de 1980, la relación entre crecimiento económico y absorción productiva de la fuerza de trabajo, junto con un Estado de bienestar incipiente - aunque limitado e imperfecto- con importantes disparidades entre países y regiones, fueron los mecanismos que alimentaron las expectativas de movilidad social de importantes sectores de la población latinoamericana. Se esperaba que los procesos de urbanización e industrialización, el desarrollo del sistema de educación pública y la expansión de las ocupaciones no manuales condujeran a la conformación de sociedades más equitativas. Estas expectativas estuvieron más cerca de materializarse en algunos países, mientras que en otros constituyeron promesas incumplidas para amplios sectores de la población. ${ }^{5}$

Aunque la capacidad de incorporación del modelo de industrialización mediante sustitución de importaciones varió mucho entre los países de la región y dentro de ellos, el funcionamiento del mercado de trabajo se caracterizó por el predominio de tendencias integradoras, con el empleo formal como punto de referencia. ${ }^{6} \mathrm{Si}$ bien los trabajadores del sector

\footnotetext{
${ }^{5}$ Los diferentes niveles y ritmos de los procesos de urbanización, industrialización y crecimiento poblacional, así como la extensión del sistema de educación pública, entre otros factores, se tradujeron en estructuras sociales heterogéneas, con diferentes pesos relativos del proletariado urbano y las clases medias en cada país.

Así, mientras que, a grandes rasgos, en 1970 Argentina y Uruguay tenían una mayor presencia de estos últimos sectores (20\% de trabajadores manuales agrícolas, $40 \%$ de trabajadores manuales no agrícolas y $40 \%$ de estratos medios y superiores), dicha presencia era ciertamente menor en México (45\%-30\%-25\%) y Brasil (50\%$30 \%-20 \%)$ y sumamente reducida en países como Guatemala (60\%30\%-10\%). Véase Gurrieri y Sainz (2003), p. 156.

${ }^{6}$ Aunque nunca logró absorber a la mayor parte de la fuerza de trabajo, entre 1950 y 1980 el empleo formal creció en forma sostenida y generó seis de cada diez nuevos empleos. Los nuevos em-
}

informal, tanto urbanos como rurales, quedaron excluidos de la provisión de bienestar — básicamente de la seguridad social—, la magnitud de dicha exclusión presentó importantes diferencias a nivel regional. ${ }^{7}$ Estas variaciones, como señala Filgueira (1998), han sido absolutamente "olvidadas" en la crítica neoliberal al modelo sustitutivo de importaciones, negligencia que impidió comprender los efectos heterogéneos del desmantelamiento de este modelo en los países de América Latina. El deterioro que esto produjo fue ciertamente más marcado y profundo en aquellos países cuyos logros integradores en el período previo habían sido mayores.

El cuadro 1 permite comparar algunas características del mercado de trabajo en Argentina y México durante el período 1950-1980. En él se observa el temprano proceso de urbanización, industrialización y asalarización de la población económicamente activa (PEA) en Argentina, así como el mayor peso en este país del empleo formal y los menores niveles de subutilización laboral -en términos de subempleo y de desempleo-, en comparación con México y con la región en su conjunto.

En Argentina - que junto con Uruguay y Chile se caracterizó por un desarrollo temprano y fue pionero en la iniciación y extensión del sistema de seguridad social- los impactos integradores del modelo de industrialización sustitutiva se tradujeron en niveles relativamente bajos de desigualdad social, pobreza y subutilización laboral hasta mediados del decenio de 1970, lo que ubicó al país en una posición privilegiada en el contexto latinoamericano. ${ }^{8}$ Dicha posición

\footnotetext{
pleos correspondieron por lo tanto en un $40 \%$ al sector informal, un $15 \%$ al sector público y el $45 \%$ restante a empresas privadas medianas y grandes (Klein y Tokman, 2000, p. 18).

${ }^{7}$ Véase en Bayón, Roberts y Saraví (1998) un análisis de la relación entre sector informal y desarrollo de la ciudadanía social en América Latina.

${ }^{8}$ Hacia 1970, los niveles de pobreza urbana en Argentina rondaban entre el $4 \%$ y el $5 \%$, y el coeficiente de Gini de la distribución del ingreso de los hogares fue de 0,41 entre 1953 y 1961, mientras que en México el valor ascendió a 0,52 y en Brasil a 0,57 (Altimir y Beccaria, 1999).
} 
América Latina, Argentina y México: Características del mercado de trabajo en América Latina, 1950-1980

(En porcentajes de la población económicamente activa - PEA)

\begin{tabular}{|c|c|c|c|c|c|c|c|}
\hline & $\begin{array}{c}\text { PEA } \\
\text { urbana }\end{array}$ & $\begin{array}{c}\text { Empleo } \\
\text { asalariado }^{\mathrm{a}}\end{array}$ & $\begin{array}{c}\text { Industria } \\
\text { manufacturera }\end{array}$ & $\begin{array}{l}\text { Servi- } \\
\text { cios }^{b}\end{array}$ & $\begin{array}{c}\text { Empleo formal } \\
\text { urbano }^{c}\end{array}$ & $\begin{array}{c}\text { Sub- } \\
\text { empleo }^{d}\end{array}$ & $\begin{array}{l}\text { Desem- } \\
\text { pleo }\end{array}$ \\
\hline \multicolumn{8}{|c|}{ América } \\
\hline \multicolumn{8}{|c|}{ Latina } \\
\hline 1950 & 43,5 & 53,6 & 14,1 & 25,7 & 30,1 & 46,5 & - \\
\hline 1980 & 64,0 & 58,9 & 18,3 & 38,2 & 44,6 & 42,2 & - \\
\hline \multicolumn{8}{|c|}{ Argentina } \\
\hline 1980 & 84,4 & 72,2 & 21,0 & 54,6 & 65,0 & 25,7 & 2,6 \\
\hline \multicolumn{8}{|c|}{ México } \\
\hline 1950 & 34,5 & 51,1 & 11,2 & 20,4 & 21,6 & 56,9 & $7,0^{\mathrm{e}}$ \\
\hline 1980 & 61,5 & 63,4 & 19,0 & 36,1 & 39,5 & 40,4 & 4,5 \\
\hline
\end{tabular}

Fuente: PREALC (1982) y CEPAL (1990).

a Los datos sobre empleo asalariado corresponden al período 1950-1970.

b Servicios incluye comercio, transporte y servicios.

c Definido por el Programa Regional del Empleo para América Latina y el Caribe (PREALC) como aquellas categorías de la PEA urbana no incluidas en el sector informal urbano.

d Definido como la suma del sector informal urbano (trabajadores por cuenta propia no profesionales, trabajadores familiares no remunerados y empleados domésticos) y trabajadores rurales tradicionales.

e Datos correspondientes a 1970 .

respondió a una conjunción de elementos, como el lento crecimiento demográfico, los mayores niveles de urbanización y asalarización, y la temprana extensión del sistema de educación pública. Los servicios sociales básicos, como salud y educación, alcanzaron una cobertura casi universal. Junto a un sector formal que proporcionaba más del $70 \%$ del empleo asalariado (Marshall, 1998), el sector informal —en el marco de un mercado interno dinámico y del crecimiento de las clases medias - adquirió rasgos particulares al no presentar las características de segmento de "refugio" o de subsistencia propias de otros países latinoamericanos. Por el contrario, lo que surgió fue un sector de trabajadores por cuenta propia con estabilidad e ingresos relativamente altos, calificación mediana y moderados niveles de productividad, en el cual un porcentaje importante de la fuerza de trabajo contaba con beneficios laborales. ${ }^{9}$

En México, aunque los alcances integradores fueron menores, el período se caracterizó por profundas y aceleradas transformaciones sociales y económicas.

\footnotetext{
${ }^{9}$ Entre mediados de la década de 1940 y el año 1970 casi la mitad del crecimiento de las actividades por cuenta propia se debió al incremento del pequeño comercio y casi 5 de cada 10 trabajadores por cuenta propia pertenecían a la clase media (Torrado, 1992). Por otro lado, los bajos costos de reparación en relación al precio de los bienes de consumo contribuyeron durante este período a que en la clase trabajadora creciera el autoempleo en actividades de reparación en mecánica, electricidad y artículos electrónicos (Marshall, 1978).
}

El proceso de industrialización y urbanización comenzó más tardíamente y a un ritmo muy rápido, transformando a un país básicamente rural y agrario en una sociedad mayoritariamente urbana y semiindustrial. ${ }^{10}$ La expansión de la cobertura de servicios básicos - tales como la educación y la atención de la saludfue acompañada por menores niveles de calidad y grandes disparidades regionales, cuantitativas y cualitativas en su provisión. La segmentación de los servicios sociales fue más profunda, no sólo por la menor cobertura de los servicios básicos, sino por la mayor extensión del sector informal. Junto a niveles de asalarización más bajos, los ingresos y beneficios vinculados al empleo formal no fueron tan significativos como en los países de desarrollo temprano (cuadro 1). Hacia 1978, y luego de un proceso de crecimiento constante en el caso de los servicios de salud, las instituciones de seguridad social sólo cubrían - nominalmente- el 38\% de la población total, mientras que un $45 \%$ de la población, integrado en gran medida por población rural, no recibía atención médica

\footnotetext{
${ }^{10}$ Entre 1940 y 1980 la economía creció a un ritmo anual de 6,4\% y la participación de la industria manufacturera en el producto se elevó de 15,4 a 24,9\%. La población urbana aumentó del 35\% al $66 \%$ y la población total casi se cuadruplicó al pasar de 20 a 70 millones; las tasas de alfabetización se duplicaron, llegando a 83\%; la escolaridad media de la población adulta se elevó de 2,6 a 4,6 años, y la esperanza de vida al nacer aumentó de 24 a 65 años (INEGI, 1985).
} 
gratuita o casi gratuita (COPLAMAR, 1985). A pesar de la reducción de la desigualdad en la distribución del ingreso experimentada entre 1963 y 1984, la inequidad en la distribución de los beneficios del crecimiento fue una característica que persistió aún en los "años dorados", y al finalizar el período el $20 \%$ más rico percibía más del 50\% del ingreso disponible, y casi seis de cada diez mexicanos seguía viviendo en condiciones de pobreza (Moreno Brid y Ros, 2004). ${ }^{11}$

La posición privilegiada de Argentina en el contexto regional comenzó a experimentar un progresivo deterioro a partir de 1975, constituyéndose en el país de América Latina que atravesó por la más profunda transformación de su estructura social en menos de tres décadas. A la par con el incremento de los niveles de desigualdad y pobreza se produjo un marcado debilitamiento de los anteriores canales de movilidad social. Si bien las transformaciones se iniciaron hacia mediados del decenio de 1970, marcando el agotamiento del modelo de desarrollo hasta entonces vigente, la década de 1990 significó la construcción de un nuevo modelo socioeconómico. Este supuso no sólo nuevos patrones de inserción del país en la economía global, sino también nuevas formas de relación de los hogares con el mercado de trabajo y con el Estado, que sacudieron y trastocaron fuertemente la estructura social argentina. ${ }^{12}$

En México, luego del estallido de la crisis de 1982, la década de 1980 trajo consigo profundas transformaciones de la estructura ocupacional, las que se tradujeron básicamente en una menor participación en el empleo de los sectores más modernos ante el avance del

\footnotetext{
${ }^{11}$ Según Cortés (2000), la baja de la concentración del ingreso entre 1963 y 1984 (cuando el índice de Gini descendió de 0,523 a 0,456) se debió principalmente al incremento de la participación relativa de los deciles intermedios y bajos ante la caída del $10 \%$ más rico; esta evolución se quebró e invirtió en los años posteriores, cuando aumentó consistentemente la participación del decil superior.

${ }^{12}$ Entre 1974 y 1991 el coeficiente de Gini pasó de 0,36 a 0,447, llegando a 0,51 en el 2000. Las diferencias de ingreso entre el decil más rico y el más pobre se triplicaron y los niveles de pobreza se cuadruplicaron: el ingreso medio per cápita del $10 \%$ más rico de los hogares en 1974 era 12 veces mayor que el del decil más pobre; en 1991 era 23 veces mayor, y en el 2000 llegó a ser 38 veces mayor. En el Gran Buenos Aires la pobreza en 1974 afectaba a no más del $5 \%$ de los hogares, cifra que subió al $9 \%$ en 1986, al $25 \%$ en 1990 luego del proceso hiperinflacionario, para descender luego a menos del $15 \%$ en 1994 y volver a trepar al $21 \%$ en el 2000 (Damill, Frenkel y Maurizio, 2002; Beccaria, Altimir y González Rozada, 2003). El empleo asalariado no registrado en el sistema de seguridad social se incrementó de $19 \%$ en 1974 a $27,3 \%$ en 1990 , llegando a $38 \%$ en el 2000, y el desempleo creció más de siete veces, al pasar de 2,6\% a 19\% entre 1980 y 2001 (Encuesta Permanente de Hogares, Instituto Nacional de Estadística y Censos).
}

empleo informal (principalmente trabajo por cuenta propia y trabajo familiar no remunerado); en términos absolutos, el empleo informal aumentó 80\% entre 1980 y 1987, llegando a absorber el $33 \%$ de la fuerza de trabajo en 1987 (CEPAL, 1989). ${ }^{13}$ La insuficiente generación de empleo estable y adecuadamente remunerado a partir de 1982, calificada por López (1999) como "desequilibrio estructural" del mercado de trabajo formal, lejos de corregirse durante el período 19881994, en que la economía mexicana entró en una etapa de expansión moderada bajo una nueva estrategia de crecimiento, se hizo más agudo, al igual que la inequidad en la distribución del ingreso. El índice de Gini pasó de 0,456 a 0,514 entre 1984 y 1992, período durante el cual la concentración del ingreso en el $10 \%$ más rico de la población se incrementó de $34,2 \%$ a $40,5 \%$ (Cortés, 2000). Una visión de la década de 1990 en su conjunto muestra una transferencia de ingresos de los hogares más pobres a los más ricos, en tanto que la posición relativa de los hogares con ingresos intermedios no registra variaciones importantes. A partir de la incorporación del país al Tratado de Libre Comercio de América del Norte, y como producto de la crisis de 1995 y sus secuelas, no sólo se desaceleró el crecimiento del poder adquisitivo de los mexicanos, sino que dicho crecimiento favoreció al 10\% más rico, a costa del deterioro de los ingresos reales del resto de los hogares, especialmente en el $30 \%$ más pobre de la población. Así, hacia el año 2000 se registraban niveles de desigualdad semejantes a los de la década de 1960 (Hernández Laos, 2003).

El análisis que se ha hecho constituye un punto de partida necesario para comprender la extensión y profundidad del deterioro social que experimentaron los países considerados a partir del decenio de 1990, así como sus impactos disruptivos sobre el tejido social. Al respecto Roberts (2004) señala que, en comparación con países como Brasil, los centroamericanos y Perú, las clases medias y trabajadoras de Argentina y Uruguay están confrontando un deterioro mucho más severo de sus niveles de vida y una más dramática reconfiguración de sus oportunidades de empleo, a lo que se agrega un elemento muy importante: la memoria de tiempos mejores. En contraste,

\footnotetext{
${ }^{13}$ Las discrepancias entre estos datos sobre empleo informal en México en 1980 y los provistos en el cuadro 1, se deben a que en dicho cuadro los cálculos se basan en la población económicamente activa urbana, mientras que los extraídos de CEPAL (1989) se refieren a la fuerza de trabajo en su conjunto.
} 
las poblaciones urbanas de muchos países latinoamericanos no tienen puntos de referencia de "tiempos dorados" para evaluar las crisis presentes. Siempre han luchado por sobrevivir. Estas diferencias afectan no sólo la vida política sino los mecanismos formales e informales para enfrentar las crisis (Roberts, 2004).

\section{III}

\section{El deterioro del mercado de trabajo: una mirada comparativa}

Pese a las similitudes de las políticas económicas aplicadas en México y Argentina, particularmente durante la primera mitad de la década de 1990 (estabilización, liberalización comercial y financiera, privatizaciones) y a la vulnerabilidad de ambos países a las perturbaciones externas, el ajuste del mercado de trabajo respectivo siguió caminos marcadamente distintos: el desempleo abierto, que partió desde niveles semejante a fines del decenio de 1980, experimentó un impresionante incremento en Argentina, mientras que permaneció en cifras muy bajas en México (gráfico 1$).{ }^{14}$

GRÁFICO 1

\section{Argentina y México: Desempleo urbano, 1980-2004 \\ (Tasas anuales medias) $^{\mathrm{a}}$}

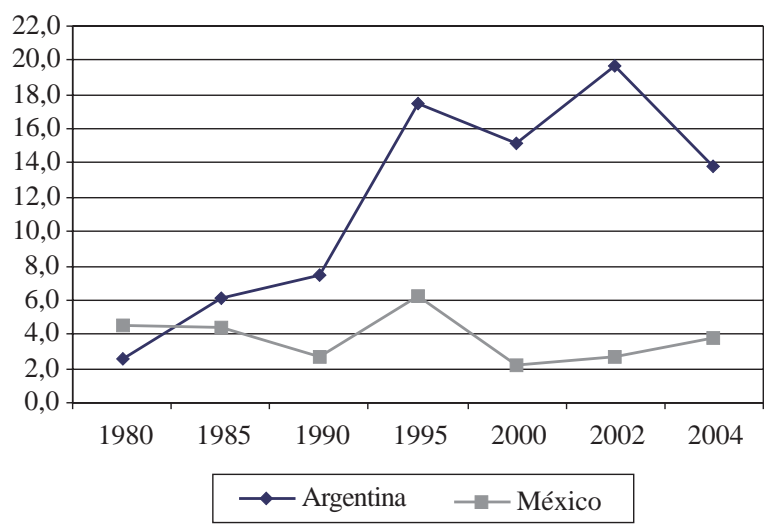

Fuente: CEPAL (2004c y 2004d).

a Tasa anual media de desempleo urbano.

\footnotetext{
${ }^{14} \mathrm{Si}$ bien el desempleo abierto se ha reducido mucho en Argentina después del 2002 y en México tiende a subir a partir del 2000, en el año 2004 Argentina seguía ubicándose entre los países de la región con más alto desempleo y México entre aquellos con desempleo más bajo.
}

En Argentina, la evolución de los indicadores de empleo, pobreza y desigualdad durante la década de 1990 fue una manifestación contundente y dolorosa de un continuo y progresivo proceso de deterioro social. No sólo estuvieron ausentes los mecanismos de protección social propios de los regímenes de bienestar europeos para hacer frente al dramático aumento del desempleo, la inseguridad laboral y la pobreza. También faltaron o fueron poco dinámicos, los "amortiguadores" o "válvulas de escape" presentes en México y algunos otros países latinoamericanos —nos referimos a la maquila, la migración y el sector informal..$^{15} \mathrm{En}$ México, estos amortiguadores contribuyeron a mantener relativamente bajos los niveles de desempleo, pero no significaron mejoras en las condiciones de vida y trabajo de amplios segmentos de la población.

Si bien en ambos países las condiciones de trabajo empeoraron en la década de 1990, el deterioro asumió características diferentes. Mientras que en Argentina el principal - aunque ciertamente no el único- mecanismo de ajuste del mercado de trabajo fue el incremento del desempleo, en México los bajos niveles de desempleo fueron acompañados por una marcada reducción de los salarios y el crecimiento del sector informal. Una tasa de desempleo abierto

\footnotetext{
${ }^{15} \mathrm{El}$ análisis de la migración de la fuerza de trabajo mexicana hacia Estados Unidos excede los objetivos de este artículo. Sin embargo, es preciso destacar que el presente análisis y las expresiones que ha adquirido el deterioro social en México en las últimas décadas ayudan a comprender las formas que asume la migración en medio de un progresivo encogimiento y deterioro de las oportunidades de empleo, haciendo de ella un fenómeno cada vez más complejo y diverso. En este sentido, Canales (2002) destaca la importancia de considerar los cambios en los patrones y perfiles migratorios en el marco de las transformaciones sociales, económicas y políticas que se han dado en México y Estados Unidos desde mediados de la década de 1980 y que han redefinido significativamente las relaciones entre ambos países.
} 
reducida, una alta ocupación en el sector informal de la economía, salarios bajos y una escasa participación de los salarios en el producto fueron algunas de las características distintivas de la economía mexicana (López, 1999). ${ }^{16}$

En contraste, en Argentina, país tradicionalmente caracterizado por mayores niveles de formalidad y protección en su mercado de trabajo, el acelerado crecimiento del desempleo y el aumento del empleo precario (subempleo y empleo sin prestaciones sociales) fue acompañado por una menor capacidad de absorción de empleo en el sector informal, especialmente en actividades por cuenta propia. De hecho, en la década de 1990, México, salvo en 1996 debido a los impactos de la profunda crisis de 1995, tuvo las tasas de desempleo más bajas de la región, mientras que en Argentina estas tasas exhibieron una tendencia ascendente, aun en los períodos de mayor crecimiento económico que se dieron en la década.

Un argumento recurrente en México es que sus bajos niveles de desempleo responden a la ausencia de un seguro de desempleo y a la escasa capacidad de ahorro de los trabajadores, quienes se ven obligados a aceptar cualquier trabajo disponible o, en su defecto, a "inventarlo". Dicho argumento, aunque relevante y con sustento empírico para un análisis dentro de las fronteras nacionales, resulta insuficiente cuando el problema se aborda desde una perspectiva comparada. El panorama ciertamente se hace más complejo cuando observamos lo sucedido en otros países de América Latina, particularmente en Argentina, donde no sólo hubo un dramático incremento del desempleo durante la década de 1990, sino que este afectó con mayor intensidad a los sectores más pobres y desprotegidos (es decir, con escasa capacidad de ahorro y un muy limitado acceso a seguro de desempleo). Tres elementos tienen particular relevancia para aprehender las múltiples dimensiones del problema.

En primer lugar, es preciso hacer explícitos los referentes de comparación. La ausencia de un seguro de desempleo como explicación de los bajos niveles de desocupación en México podría ser relativamente válida cuando se compara a México con los países europeos - entre los cuales, sin embargo, los sistemas de protección son muy heterogéneos y el tema es en sí

\footnotetext{
${ }^{16}$ El salario real mínimo en el año 2000 representaba un tercio del monto de 1980 y los sueldos y salarios pagados en las empresas manufactureras de mayor tamaño habían caído a menos del $40 \%$ del nivel que tenían en 1990 (Salas y Zepeda, 2003, p. 65).
}

mismo objeto de un amplio debate-.${ }^{17}$ Pero no contribuye a explicar los bajos niveles de desempleo mexicanos en comparación con los de América Latina. Los seguros de desempleo "realmente existentes" en la región - en los países que cuentan con ellos- presentan grandes limitaciones, tanto por su bajísima cobertura (en un contexto en el cual el trabajo formal y estable está lejos de constituir la norma) como por los reducidos montos de la compensación. Difícilmente la presencia de un seguro de desempleo cuya cobertura nunca abarcó más del $6 \%$ de los desocupados contribuya a explicar por qué más del $20 \%$ de la población económicamente activa en Argentina se ha llegado a definir como desempleada en momentos de profundas crisis económicas, mientras que en México el porcentaje correspondiente nunca ha superado el $6 \%$ (gráfico 1). ${ }^{18}$

El segundo elemento es la relación entre pobreza y desempleo. La fuerte asociación y retroalimentación entre ambos en el caso argentino cuestiona la concepción del desempleo como un "lujo" de los sectores con mayores niveles educativos y capacidad de ahorro que los pobres "no pueden" darse. Si bien a partir del decenio de 1990 el desempleo se extendió al conjunto de las categorías ocupacionales y niveles educativos, afectó con mayor intensidad a los grupos más desfavorecidos en términos de educación y calificación. Según datos relativos al Gran Buenos Aires, la incidencia del desempleo en el $10 \%$ más pobre de la población pasó de $14,3 \%$ a 29,8\% entre 1990 y 2000 (Encuesta Permanente de Hogares, INDEC).

En relación a lo anterior, el tercer elemento, frecuentemente ignorado, es el influjo de las tradiciones laborales en la manera en que el trabajo y el desempleo

\footnotetext{
${ }^{17}$ Como emerge del análisis comparado de países de la Unión Europea, hay escasa evidencia empírica de que los beneficios sociales - y específicamente la existencia de un seguro de desempleo- reduzcan los incentivos para trabajar o, en otros términos, que estimulen el desempleo. El problema es ciertamente más complejo y depende no sólo de la extensión y monto de los beneficios, sino también de la interacción de las políticas (por ejemplo, beneficios sociales y políticas activas del mercado de trabajo). Entre otros trabajos, véase Esping-Andersen y Regini (2000) y Gallie y Paugam (2000).

${ }^{18}$ En Argentina, la Ley nacional de empleo aprobada en 1991 incorporó el seguro de desempleo, pero ligado al empleo estable y sólo limitado a ciertos segmentos del sector formal, lo que explica su escasa cobertura en una situación de extendida inseguridad laboral. Tienen derecho a solicitar el seguro de desempleo aquellos trabajadores despedidos sin causa justa de un empleo registrado y que hayan hecho aportes a la seguridad social durante al menos 12 meses de los 36 previos al despido. Cubre a los asalariados incluidos en la Ley de Contratos de Trabajo, por lo que excluye a los trabajadores de la construcción (quienes tienen su propio esquema), el servicio doméstico, el sector público y las actividades rurales.
} 
se definen y experimentan. Dichas tradiciones son los marcos de referencia que permiten comprender en qué medida el desempleo constituye una categoría claramente reconocible. Evidencias cualitativas muestran que en Argentina - cuyo mercado laboral se caracterizó históricamente en la región por tener mayores niveles de empleo formal — la estabilidad y los derechos asociados al "trabajo" afectan no sólo la percepción acerca de qué es un "buen trabajo", sino la definición misma de trabajo y pertenencia social, incluso en un contexto de profunda precarización laboral (Bayón, 2002). Los derechos laborales tienden a estar ligados al concepto mismo de empleo, incluso entre aquellos trabajadores de sectores de menores ingresos y escasa calificación que nunca tuvieron acceso pleno a esos derechos. En efecto, la expresión "changa", que hace referencia a trabajos temporales, es utilizada localmente para expresar toda aquella actividad que "no" es considerada trabajo.

En contraste, en sociedades como la mexicana, caracterizadas por fuertes tradiciones y circuitos de empleo y consumo informales en las cuales el empleo asalariado estuvo históricamente menos extendido, el trabajo tiende a estar más asociado a la generación de ingresos que a la estabilidad y la protección, y el desempleo aparece como una categoría menos reconocible por la población. ${ }^{19}$ Como señalan diversos estudios sobre México, y como lo confirma la cotidianidad urbana, las actividades por cuenta propia o, en otros términos, la capacidad de "inventar" formas de obtener ingresos para cubrir las necesidades del hogar, ha constituido una tradición de trabajo familiar en los sectores populares (Estrada Iguiñiz, 1996). Según Selby, Murphy y Lorenzen (1994), para los pobres urbanos es más importante proveer a la familia con los recursos necesarios para subsistir que conservar un mismo empleo en forma estable: frases como "buscando la manera", "haciéndole la lucha", "poniéndose abusado", etc., revelan con mayor vitalidad y crudeza esa actitud de "entrarle a todo" para sobrevivir que define la mentalidad del citadino pobre.

El análisis comparado de las diversas formas que ha asumido el ajuste del mercado de trabajo, si bien no se agota en los elementos descritos, contribuye a realzar la naturaleza multidimensional del problema. Con el mismo fin, a continuación se examinan tres

\footnotetext{
${ }^{19}$ En el mismo sentido, Gallie, Jacobs y Paugam (2000) observan que en el sur de Italia la mayor extensión de la precariedad laboral altera el modo en que el desempleo es percibido y experimentado, así como las expectativas de futuro laboral, puesto que la economía informal opera como el principal medio para enfrentar la pobreza y la desprotección social.
}

dimensiones de particular importancia para comprender las diferentes formas que ha tomado el deterioro laboral en los dos países considerados. La primera destaca la relación entre los cambios en la estructura del empleo y el tipo de inserción en la economía internacional. La segunda hace hincapié en el problema del empleo informal y la desprotección social. La tercera explora las formas que adquiere la relación entre trabajo, desempleo y pobreza en uno y otro país.

\section{Modelo exportador y empleo manufacturero}

Como muestra la estructura de sus exportaciones, Argentina y México representan modelos contrastantes de inserción en el mercado internacional: en el primer caso hay una marcada especialización en bienes que hacen uso intensivo de recursos naturales y, en el segundo, una fuerte orientación a la manufactura (maquiladora y no maquiladora). Mientras que los bienes primarios representaron el $71 \%$ de las exportaciones de Argentina en 1990 y el 66\% en el 2001, la participación de las manufacturas - que en su gran mayoría hacen uso intensivo de trabajo- en las exportaciones de México se incrementó de $43 \%$ a $85 \%$ entre esos mismos años (PNUD, 2003).

Este patrón de especialización tiene diferentes repercusiones en la generación de empleo, especialmente manufacturero. Argentina experimentó un marcado proceso de desindustrialización desde mediados de la década de 1970, y su sector manufacturero se transformó en un expulsor de fuerza de trabajo: entre 1976 y 2001 el empleo en la industria manufacturera cayó 66\%. En el decenio de 1990, la apertura comercial y la sobrevaluación del tipo de cambio transformaron radicalmente los precios relativos del trabajo y el capital, afectando negativamente la demanda de trabajo en el sector de bienes transables, e incentivando la sustitución de trabajo por capital, lo que se tradujo en un fuerte incremento de la productividad. ${ }^{20}$ Las empresas que lograron sobrevivir acrecentaron su inversión en bienes de capital, reduciendo la planta de trabajadores incluso durante la breve fase expansiva que se hizo sentir entre 1991 y 1994 . A esto se sumó la destrucción de empleo debida al cierre de pequeñas y medianas empresas industriales y a la racionalización de los procesos de trabajo sin efectuar mayores inversiones en capital fijo. A pesar del alto crecimiento económico argentino en los primeros

\footnotetext{
${ }^{20}$ Luego de la devaluación de la moneda a fines de 2001 este sector ha mostrado un mayor dinamismo en la generación de empleo, creciendo 16\% entre 2002 y 2004 (Encuesta Industrial Mensual, INDEC).
} 
años de la década —básicamente entre 1991 y 1994_ el desempleo creció casi sin interrupciones desde 1991 (Katz, Bisang y Burachik, 1995; Heymann, 2000).

Entre 1991 y 1999, el empleo manufacturero disminuyó 46,6\% en Argentina y en cambio subió 28,8\% en México (Stallings y Weller, 2001). Esto pone de manifiesto el papel amortiguador desempeñado por la industria maquiladora mexicana — cuya participación en el empleo industrial pasó de $14 \%$ a $30 \%$ entre 1990 y el 2000 — ante la destrucción de empleos manufactureros en otros sectores. Sin embargo, el dinamismo del empleo de maquila, que se duplicó en sólo cinco años al pasar de 650.000 en 1995 a casi 1.300.000 en el año 2000, ha comenzado a mostrar signos de agotamiento. En sólo tres años (entre el 2000 y el 2003) se perdieron casi 230.000 empleos de maquila, y la participación del empleo manufacturero en el empleo urbano se redujo de $29,3 \%$ a $26 \%$ (INEGI, 1985; OIT, 2004).

Los trabajadores desplazados del sector manufacturero y el incremento de la oferta laboral en México fueron absorbidos principalmente por la expansión del empleo en el sector de servicios, donde aumentó el empleo de tiempo completo, sobre todo en actividades asociadas a una mayor proporción de trabajo informal, como el comercio: este sector ofreció uno de cada cuatro de los nuevos empleos que se generaron en la década de 1990 (Frenkel y Ros, 2004).

En Argentina, no sólo la pérdida de empleos manufactureros fue mayor que en México, sino que el empleo de tiempo completo en casi todos los sectores de bienes no transables — con la parcial excepción de los servicios financieros, las comunicaciones y el transporte- se mantuvo estancado entre 1991 y el 2000, por lo que no contribuyó a contrapesar la destrucción de empleo en otros sectores de la economía. El dinamismo del empleo en el sector de servicios se tradujo fundamentalmente en un incremento persistente del subempleo. ${ }^{21}$ En el Gran Buenos Aires el subempleo pasó de $8,3 \%$ a $15,1 \%$ entre 1990 y el 2000, llegando a 16,8\% en 2004 (Encuesta Permanente de Hogares, INDEC), y constituyó una de las expresiones más evidentes del deterioro laboral en términos de ingresos y desprotección social. ${ }^{22}$ Así, la pérdida de empleos de

\footnotetext{
${ }^{21}$ Se refiere a los ocupados que trabajan menos de 35 horas semanales por causas involuntarias y que desean trabajar más horas.

${ }^{22}$ En octubre de 2000, siete de cada diez trabajadores de tiempo parcial eran subocupados y entre los últimos el 71,4\% carecía de beneficios sociales (Encuesta Permanente de Hogares, INDEC). Mientras que el ingreso real medio de los asalariados de tiempo completo se incrementó $17 \%$, el de los subocupados cayó $15 \%$ entre los años 1991 y 2000 (Damill, Frenkel y Maurizio, 2002).
}

tiempo completo en la manufactura fue parcialmente compensada por el subempleo en el sector de servicios, el cual, por su carácter contracíclico, desempeñó un papel semejante al que tuvo el sector informal en México (Frenkel y Ros, 2004).

\section{Informalidad y desprotección}

En Argentina, los altos niveles de desempleo fueron acompañados por una pérdida de dinamismo del autoempleo, lo que agudizó la vulnerabilidad a la exclusión laboral de amplios contingentes de trabajadores, sobre todo entre los de mediana edad y bajos niveles educativos. ${ }^{23}$ Como se observa en el cuadro 2 , mientras que en Argentina el trabajo por cuenta propia redujo su participación en el empleo informal de $22,9 \%$ a $17,5 \%$ entre 1990 y 2002, en México dicha participación se elevó de $19 \%$ a $21 \%$ durante el mismo período. El comportamiento del autoempleo en el comercio y los servicios ofrece un particular contraste: disminuyó de $16 \%$ a 10,7\% en Argentina, y subió de $12,5 \%$ a $16,1 \%$ en México.

A diferencia de lo ocurrido en las décadas previas, en el decenio de 1990 México vio desacelerarse el crecimiento del empleo asalariado, cuya participación en la PEA ocupada disminuyó de 76,4\% a 73,1\% entre 1989 y $2002 .{ }^{24}$ La baja de la participación del sector público en el empleo asalariado — de 16,1\% a 13,2\% entre 1994 y 2002 - y la caída del empleo en las empresas con más de cinco trabajadores — de $48,1 \%$ a $32 \%$ en el mismo período - contribuyen a explicar dicha desaceleración (CEPAL, 2003). El mayor dinamismo del empleo se generó en los sectores tradicionalmente más precarios —las microempresas, el servicio doméstico y el trabajo por cuenta propia no calificado- que en el 2002 concentraban casi la mitad de la población urbana ocupada. En otros términos, cinco de cada diez trabajadores mexicanos están "incorporados" en los segmentos más precarios del mercado de trabajo, donde los niveles de desprotección

\footnotetext{
${ }^{23} \mathrm{El}$ menor dinamismo del empleo por cuenta propia respondió, entre otros factores, a la desaparición de numerosos pequeños comercios y talleres que no pudieron competir con las grandes cadenas de supermercados y la entrada masiva de productos importados, así como a la reducción de las oportunidades de empleo en ciertos servicios (como los de reparación, por el mayor acceso al crédito para adquirir bienes de consumo durables a principios de la década).

${ }^{24}$ Entre 1970 y 1990 el empleo asalariado creció $154 \%$ y el empleo por cuenta propia $87 \%$. Sin embargo, la relativa generalización del empleo asalariado sólo se había logrado en la industria manufacturera, puesto que en el comercio, y en menor medida en los servicios, era mayor la presencia de empleo no asalariado (Rendón y Salas, 2000).
} 
Argentina y México: Población ocupada en el sector informal, 1980-2002 (En porcentajes del total de la población urbana ocupada)

\begin{tabular}{|c|c|c|c|c|c|c|c|}
\hline & \multirow[b]{2}{*}{ Total } & \multicolumn{2}{|c|}{ Microempresas } & \multirow{2}{*}{$\begin{array}{c}\text { Empleo } \\
\text { doméstico }\end{array}$} & \multicolumn{3}{|c|}{$\begin{array}{c}\text { Trabajadores independientes } \\
\text { no calificados }\end{array}$} \\
\hline & & Empleadores & Asalariados & & Total & $\begin{array}{l}\text { Industria y } \\
\text { construcción }\end{array}$ & $\begin{array}{c}\text { Comercio y } \\
\text { servicios }\end{array}$ \\
\hline \multicolumn{8}{|c|}{ Argentina } \\
\hline 1980 & 48,9 & 2,6 & 10,2 & 3,9 & 32,2 & 6,5 & 25,7 \\
\hline 1997 & 41,4 & 3,7 & 15,9 & 5,1 & 16,7 & 4,6 & 12,1 \\
\hline 2000 & 42,2 & 3,4 & 16,0 & 5,3 & 17,5 & 5,1 & 12,4 \\
\hline 2002 & 42,1 & 2,9 & 16,1 & 5,6 & 17,5 & 6,8 & 10,7 \\
\hline \multicolumn{8}{|c|}{ México } \\
\hline 1984 & $\ldots$ & $\ldots$ & $\ldots$ & 2,6 & 24,7 & 2,1 & 14,0 \\
\hline 1989 & $\ldots$ & $\ldots$ & $\ldots$ & 2,7 & 18,9 & 3,0 & 12,5 \\
\hline 1996 & 43,7 & 3,8 & 15,8 & 3,6 & 20,4 & 3,8 & 15,7 \\
\hline 2000 & 42,5 & 3,9 & 16,0 & 3,0 & 19,6 & 3,6 & 15,1 \\
\hline 2002 & 47,2 & 3,4 & 18,3 & 4,6 & 20,9 & 4,2 & 16,1 \\
\hline
\end{tabular}

Fuente: Panorama social de América Latina (CEPAL, varios años).

CUADRO 3

Argentina y México: Algunos indicadores de protección social, 1990-2001 (Porcentajes)

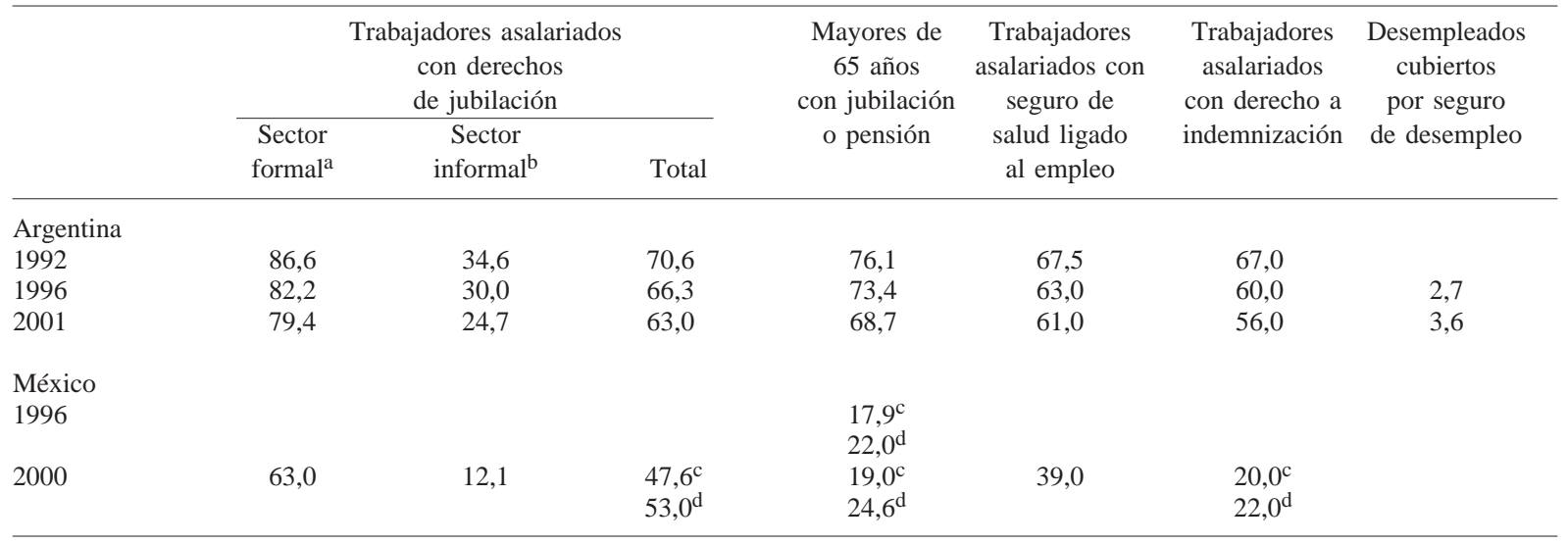

Fuente: OIT (2003); Gasparini, 2004.

a Asalariados de empresas con más de cinco trabajadores y del sector público.

b Asalariados de empresas con cinco o menos trabajadores.

c Total nacional.

d Total urbano.

alcanzan niveles alarmantes: sólo uno de cada diez trabajadores del sector informal tiene acceso a derecho de jubilación (cuadro 3). Sin embargo, los trabajadores informales no son los únicos desprotegidos: según datos del 2000, cuatro de cada diez trabajadores asalariados del sector formal (ocupados en empresas de mayor tamaño o en el sector público) carecían de esos derechos. El resultado es que en México, el país latinoamericano con menores niveles de desempleo, la gran mayoría de los trabajadores está desprotegida, situación que ha tendido a agudizarse en los últimos años: la población ocupada sin prestaciones sociales (asalariada y no asalariada) se elevó de $61,4 \%$ a $63 \%$ entre el 2001 y el 2004, alcanzando el $64 \%$ en el primer trimestre del $2005{ }^{25}$

25 INEGI $(2001,2004$ y 2005). 
El cuadro 3 muestra cuán profundo fue el deterioro del empleo en Argentina durante el decenio de 1990. Sin embargo, pese a la intensidad y extensión de la inseguridad laboral, inéditos en la historia del país, los niveles de protección social argentinos, según diversos indicadores, siguen siendo superiores a los de México. Las diferencias más evidentes entre ambos países tienen que ver con la cobertura de la jubilación o pensión entre los mayores de 65 años $(68,7 \%$ en Argentina frente a $20 \%-25 \%$ en México), el acceso a seguro de salud ligado al empleo $(61 \%$ frente a $39 \%$, respectivamente) y el derecho a indemnización entre los asalariados (56\% frente a $20 \%)$.

Los mayores niveles de protección social en Argentina ocultan una marcada inequidad en su distribución. Según datos de la Encuesta de Condiciones de Vida realizada en 2001, el 64,2\% de la población mayor de 65 años contaba con algún tipo de cobertura previsional, ya fuese de naturaleza contributiva o no contributiva. Sin embargo, dicha protección se reducía a la mitad $(32,2 \%)$ en el $20 \%$ más pobre y a $57,2 \%$ en el segundo quintil, mientras que ascendía a 78,5\% en el quintil más alto (OIT/MECON, 2005).

\section{Precariedad laboral, desempleo y pobreza}

El nexo entre inestabilidad laboral, pobreza y desprotección social se expresa de manera diversa en los casos analizados. Algunos autores señalan que, en términos generales, ser un trabajador en América Latina equivale a ser pobre, por lo que no es necesario estar desempleado para situarse por debajo de los umbrales de la pobreza (Portes y Hoffman, 2003). Sin embargo, los casos de México y Argentina introducen importantes matices que ayudan a comprender mejor las características específicas del problema en contextos particulares.

La asociación entre empleo y pobreza ha sido particularmente dispar en los casos de México y Argentina, al menos hasta fines del decenio de 1990. Como se observa en el cuadro 4 , los segmentos más dinámicos del mercado de trabajo en México fueron precisamente aquellos con mayor incidencia de la pobreza y la desprotección social. En el 2002, la pobreza urbana afectaba al $32 \%$ de la población urbana y al $25 \%$ de los ocupados. Este porcentaje se elevaba al $40 \%$ entre los asalariados de microempresas, al $46 \%$

Argentina (zonas urbanas) y México: Incidencia de la pobreza en algunas categorías ocupacionales, 1990-2002

(En porcentajes del total de la población urbana ocupada)

\begin{tabular}{|c|c|c|c|c|c|c|c|}
\hline & \multirow[b]{2}{*}{$\begin{array}{c}\text { Total } \\
\text { población }\end{array}$} & \multirow[b]{2}{*}{$\begin{array}{c}\text { Total } \\
\text { ocupados }\end{array}$} & \multicolumn{3}{|c|}{$\begin{array}{l}\text { Asalariados del sector privado } \\
\text { no profesionales ni técnicos }\end{array}$} & \multicolumn{2}{|c|}{$\begin{array}{c}\text { Trabajadores por cuenta propia } \\
\text { no profesionales }\end{array}$} \\
\hline & & & $\begin{array}{c}\text { Empresas } \\
\text { con más de } 5 \\
\text { trabajadores }\end{array}$ & $\begin{array}{l}\text { Empresas } \\
\text { con hasta } 5 \\
\text { trabajadores }\end{array}$ & $\begin{array}{c}\text { Empleo } \\
\text { doméstico }\end{array}$ & $\begin{array}{c}\text { Industria } \\
\text { y construcción }\end{array}$ & $\begin{array}{c}\text { Comercio } \\
\text { y servicios }\end{array}$ \\
\hline \multicolumn{8}{|c|}{$\begin{array}{l}\text { Argentina } \\
\text { (Gran Buenos Aires) }\end{array}$} \\
\hline 1990 & 21 & 10 & $\ldots$ & 15 & 21 & 6 & 8 \\
\hline 1994 & 13 & 5 & $\ldots$ & 7 & 10 & 4 & 3 \\
\hline 1997 & 18 & 8 & & 12 & 18 & 8 & 6 \\
\hline 1999 & 20 & 10 & 9 & 17 & 22 & 14 & 3 \\
\hline 2002 & 42 & 27 & 31 & 40 & 43 & 31 & 19 \\
\hline \multicolumn{8}{|c|}{ México } \\
\hline 1989 & 42 & 33 & $\ldots$ & $\ldots$ & 60 & 32 & 28 \\
\hline 1994 & 37 & 29 & $\ldots$ & $\ldots$ & 56 & $\ldots$ & $\ldots$ \\
\hline 1996 & 45 & 38 & 41 & 59 & 63 & 48 & 41 \\
\hline 1998 & 39 & 31 & 36 & 49 & 57 & 39 & 30 \\
\hline 2000 & 32 & 25 & 26 & 44 & 38 & 34 & 24 \\
\hline 2002 & 32 & 25 & 27 & 40 & 46 & 27 & 21 \\
\hline
\end{tabular}

Fuente: CEPAL (2003). 
entre los empleados domésticos, y al $27 \%$ entre los asalariados de empresas con más de cinco trabajadores y entre los trabajadores no profesionales por cuenta propia en la industria y la construcción, segmentos que concentran la mitad de la PEA urbana ocupada.

En Argentina, si bien los niveles de pobreza en la población total superaron a los de México en 2002, la incidencia de la pobreza entre los ocupados fue similar en ambos países, lo que estaría indicando una más fuerte asociación entre empleo y pobreza en México, y una mayor la incidencia del desempleo en los sectores de menores ingresos en Argentina. Esto significa que si bien en Argentina no es necesario estar desempleado para ser pobre, los sectores pobres son particularmente vulnerables a caer en situaciones de desempleo, como lo pone de manifiesto el perfil laboral de los hogares pobres en ambos países (cuadro 5). Aunque la incidencia de la pobreza en la población ocupada es menor en Argentina, cabe destacar que entre 1999 y 2002 creció más aceleradamente que la pobreza en la población total, por lo que los bajos salarios que han caracterizado a los puestos de trabajo surgidos durante este período podrían estar acercando a Argentina a las tendencias observadas en el caso mexicano. Se trata, nuevamente, de una nivelación hacia abajo, producto del deterioro del empleo en Argentina y no de un mejoramiento en México.

El perfil laboral de los hogares pobres muestra que el incremento de las tasas de participación se observa en ambos países, si bien fue más intenso en Argentina. Con niveles de participación similares en ambos países en el 2002, en Argentina los hogares pobres exhiben una menor densidad ocupacional y mayores niveles de desempleo, a la par de un marcado deterioro del ingreso medio de los miembros del hogar ocupados. Es decir, la estrategia de enviar más miembros del hogar al mercado de trabajo tuvo efectos diferentes en uno y otro caso: elevó la densidad ocupacional de los hogares pobres en México - aunque con muy bajos ingresos-, mientras que incrementó el número de miembros del hogar desocupados en Argentina, donde dicha estrategia fue mucho menos eficaz (cuadro 5). Así, al problema de los trabajos precarios (inestables, con bajos salarios, desprotegidos, etc.) se suma el problema de la falta de trabajo. No se trata sólo de ingresos insuficientes, sino de ausencia de ingresos ante la alternancia de empleos precarios y recurrentes períodos de desempleo.

El cuadro 6 no sólo nos permite explorar las características laborales de los hogares pobres en México y Argentina, sino comparar su inserción laboral con la de los hogares que logran superar los niveles de pobreza en ambos países. En Argentina, durante el período 1999-2003, se observa la dramática incidencia del desempleo en los hogares pobres: en el 35,7\% de ellos hay al menos un miembro desocupado, y en uno de cada cuatro hogares hay al menos dos desocupados. En México, en cambio, las proporciones respectivas son inferiores a $6 \%$ y $1 \%$. Cuando comparamos hogares pobres y no pobres, se observa que en Argentina la presencia de al menos dos miembros ocupados en el hogar contribuye a reducir la vulnerabilidad a la pobreza: esto sucede en casi $40 \%$ de los hogares que superan los umbrales de pobreza, pero sólo en $25,5 \%$

CUADRO 5

Argentina (zonas urbanas) y México: Perfil laboral de los hogares pobres, 1990-2002 (Porcentajes)

\begin{tabular}{|c|c|c|c|c|c|c|}
\hline & $\begin{array}{l}\text { Tasa de } \\
\text { pobreza }\end{array}$ & $\begin{array}{c}\text { Tamaño medio } \\
\text { del hogar }\end{array}$ & $\begin{array}{c}\text { Tasa de } \\
\text { participación }^{\mathrm{a}}\end{array}$ & $\begin{array}{c}\text { Tasa de } \\
\text { desocupación }^{\mathrm{b}}\end{array}$ & $\begin{array}{c}\text { Densidad } \\
\text { ocupacional }^{\mathrm{c}}\end{array}$ & $\begin{array}{l}\text { Ingreso medio } \\
\text { de los ocupados }\end{array}$ \\
\hline \multicolumn{7}{|c|}{ Argentina } \\
\hline 1990 & 16,2 & 4,51 & 0,47 & $\ldots$ & 0,16 & 2,5 \\
\hline 2002 & 31,6 & 4,5 & 0,64 & 0,26 & 0,25 & 1,57 \\
\hline \multicolumn{7}{|c|}{ México } \\
\hline 1990 & 39,0 & 6,03 & 0,58 & $\ldots$ & 0,29 & 1,6 \\
\hline 2002 & 31,8 & 5,1 & 0,65 & 0,03 & 0,35 & 1,33 \\
\hline
\end{tabular}

Fuente: CEPAL (2004a).

a Población económicamente activa (PEA), incluyendo ocupados y desocupados / Población en edad de trabajar.

b Número de desocupados / PEA.

c Número de ocupados / número de miembros del hogar.

d Expresado como fracción del valor de la línea de pobreza. 
Argentina (zonas urbanas) y México: Características laborales de hogares pobres y no pobres, 1999-2003

(Porcentaje de hogares según la condición de actividad de sus miembros)

\begin{tabular}{|c|c|c|c|c|c|c|}
\hline & $\begin{array}{l}\text { Al menos } \\
1 \text { ocupado }\end{array}$ & $\begin{array}{c}\text { Al menos } \\
2 \text { ocupados }\end{array}$ & $\begin{array}{c}\text { Al menos } \\
1 \text { desocupado }\end{array}$ & $\begin{array}{c}\text { Al menos } \\
2 \text { desocupados }\end{array}$ & $\begin{array}{c}\text { Jefe } \\
\text { inactivo }\end{array}$ & $\begin{array}{l}\text { Ocupados en el } \\
\text { sector informal }\end{array}$ \\
\hline & \multicolumn{6}{|c|}{ A. Hogares no pobres } \\
\hline Argentina & 76,9 & 39,2 & 14,2 & 1,2 & 30,7 & 39,8 \\
\hline \multirow[t]{2}{*}{ México } & 92,1 & 51,9 & 3,9 & 0,7 & 16,2 & 51,3 \\
\hline & \multicolumn{6}{|c|}{ B. Hogares pobres } \\
\hline Argentina & 76,6 & 25,5 & 35,7 & 9,2 & 23,3 & 47,3 \\
\hline México & 93,1 & 46,5 & 5,3 & 0,9 & 13,9 & 69,7 \\
\hline
\end{tabular}

Fuente: CEPAL (2004a).

de los hogares pobres. En México, por el contrario, la presencia de al menos dos ocupados se observa en el $46,5 \%$ de los hogares pobres y el 51,9\% de los hogares no pobres, lo que no parece constituir una diferencia significativa. La diferencia más notoria es la mayor presencia de miembros ocupados en el sector in- formal en los hogares de menores ingresos: si bien no todos los ocupados en el sector informal son pobres - como lo muestra la alta participación de los miembros de hogares no pobres en dicho sector- en los hogares pobres la mayoría de sus miembros está ocupada en el sector informal.

\section{IV}

\section{Desigual distribución de oportunidades y entrampamiento en situaciones de desventaja}

El análisis que hemos hecho de las relaciones entre la pobreza y la precariedad laboral, en sus diferentes expresiones, muestra la progresiva erosión de los anteriores mecanismos de supervivencia económica y obtención de ingresos. La posibilidad de "ganarse la vida" trabajando, al menos de manera continuada, es cada vez más incierta.

El profundo debilitamiento del trabajo y la educación como canales de movilidad social - o al menos como fuentes que alimentaban expectativas de mejoramiento futuro- , junto con la creciente inequidad en la distribución de oportunidades ocupacionales y educativas, dan cuenta de una estructura social que se hace cada vez más rígida. En otras palabras, el margen de maniobra para superar situaciones de desventaja social entre quienes provienen de hogares desfavorecidos —en cuanto a ingreso, empleo, educa- ción, vivienda y otros aspectos- se estrecha progresivamente en un contexto cada vez más hostil para quienes no están dotados de partida de fuertes habilidades cognitivas y destrezas sociales. La carencia de estos recursos conduce al entrampamiento en oportunidades de vida signadas por una "espiral de precariedad" en la cual las desventajas se retroalimentan y acumulan (Paugam, 1995).

Estos procesos se pusieron de manifiesto con mayor crudeza tras las reformas introducidas en el área social durante la década de 1990, que no sólo fueron el correlato del ajuste en el área económica, sino que contribuyeron a acentuar la vulnerabilidad de amplios sectores de la población. La provisión universal de servicios de salud y educación por parte del Estado fue calificada de ineficiente al favorecer a los sectores medios en detrimento de los estratos de más bajos 
ingresos. Para cambiar ese "sesgo" distributivo y descentralizar los servicios se recurrió a estrategias de focalización. El resultado fue lo que Bustelo (1992), retomando la expresión acuñada por Fernando Henrique Cardoso, caracterizó como el "Estado de malestar", que se tradujo en el desmantelamiento de las áreas en las que el incipiente Estado de bienestar había alcanzado cierto desarrollo. En su dimensión psicosocial este fenómeno se expresa en el congelamiento de las perspectivas de movilidad ascendente, una caída de las expectativas de una mejor calidad de vida y un discurso de un individualismo dogmático que deja a cada persona librada a su propia suerte en medio de una creciente polarización social (Bustelo, 1992).

\section{Rigidización de la estructura social}

\section{a) La desigual distribución de oportunidades educativas}

La distribución de oportunidades educativas constituye una de las pruebas más contundentes de que se ha hecho más profunda la brecha que separa a los sectores más y menos favorecidos. Esta inequidad adquiere particular relevancia en un escenario en el cual el acceso al conocimiento es un recurso clave para acceder a las oportunidades que los procesos en marcha ofrecen, y la carencia de ese acceso potencia y acelera los procesos de exclusión en los sectores más desfavorecidos.

Reimers (2000) destaca cinco procesos a través de los cuales la desigualdad en la distribución del ingreso se traduce en desiguales oportunidades educativas en América Latina: i) el acceso diferenciado a distintos niveles educativos entre pobres y no pobres; ii) el tratamiento diferenciado que pobres y no pobres reciben en la escuela, donde los primeros adquieren una educación de menor calidad; iii) la tendencia — cada vez más marcada- de los estudiantes a relacionarse sólo con pares de la misma condición socioeconómica; iv) la contribución de los padres a la educación de sus hijos, que es mayor mientras más alto sea el nivel educativo del hogar, y v) la existencia de contenidos y procesos educativos que no están orientados específicamente a reducir la desigualdad.

Las relaciones entre la distribución del ingreso y la distribución de oportunidades educativas ayudan a explicar el peso y valor social que históricamente ha tenido la educación en Argentina y México, por su potencial integrador y como canal de movilidad so- cial. ${ }^{26}$ Hacia mediados del decenio de 1990, la relación entre la distribución de las oportunidades educativas y la distribución del ingreso muestra comportamientos inversos en uno y otro país. Entre 19 países latinoamericanos, Argentina ocupaba el primer lugar en términos de equidad educativa y el quinto en términos de distribución del ingreso, mientras que México se ubicaba en el lugar $12^{\circ}$ y el $8^{\circ}$, respectivamente (Reimers, 2000, cuadro 4.1). Es decir, en Argentina las distancias sociales en términos de ingresos han sido históricamente mayores que las distancias educativas, mientras que en México la altamente desigual distribución del ingreso va acompañada de una desigualdad todavía mayor en la distribución de oportunidades educativas. Esto contribuye a explicar el papel clave que tuvo la extensión del sistema de educación pública en $\mathrm{Ar}$ gentina como vía de movilidad social y fuente de integración y pertenencia social. Este rol de la educación es mucho más débil en México, donde la amplia brecha educativa existente entre los sectores de mayores y de menores ingresos, la alta segmentación vinculada a la calidad de la educación y los muy bajos niveles educativos del $40 \%$ más pobre de la población constituyen evidencias dramáticas de las abismales distancias sociales que han caracterizado a la estructura social mexicana (cuadro 7).

CUADRO 7

Argentina y México: Años de educación en la población adulta, ${ }^{a}$ por quintil de ingreso, 1992-2001

\begin{tabular}{|c|c|c|c|c|}
\hline \multirow[b]{2}{*}{ Quintiles } & \multicolumn{2}{|c|}{1992} & \multicolumn{2}{|c|}{2001} \\
\hline & Argentina & México & Argentina & México \\
\hline 1 & 7,5 & 2,7 & 7,3 & 3,5 \\
\hline 2 & 8,0 & 4,1 & 8,3 & 5,3 \\
\hline 3 & 8,7 & 6,6 & 9,2 & 8,1 \\
\hline 4 & 9,8 & 6,6 & 10,6 & 8,1 \\
\hline 5 & 12,2 & 10,0 & 13,4 & 11,6 \\
\hline Promedio & 9,5 & 6,1 & 10,1 & 7,4 \\
\hline $\begin{array}{l}\text { Brecha educativa } \\
\text { (Q5-Q1) }\end{array}$ & 4,7 & 7,3 & 6,1 & 8,1 \\
\hline
\end{tabular}

Fuente: Banco Mundial (2003).

a Población de 25 a 65 años.

\footnotetext{
${ }^{26}$ En América Latina el coeficiente de Gini de educación (que mide la desigualdad en la distribución de la educación) fue de 50,1 en 1960, de 47,0 en 1970, de 43,1 en 1980 y de 41,8 en 1990. En esos mismos años los valores de dichos coeficientes en Argentina fueron respectivamente de 34,4, de 31,1, de 29,4 y de 27,3, y en México de 56,0, de 51,0, de 49,7 y de 38,4 (Banco Mundial, 2003). Estos valores muestran la mayor equidad educativa que históricamente ha caracterizado a Argentina en el contexto regional.
} 
Nuevamente, los efectos disruptivos del modelo económico neoliberal han sido más profundos en Argentina, donde la brecha educativa entre el $20 \%$ más rico y el $20 \%$ más pobre se amplió incluso más que en México, al pasar de 4,7 a 6,1 (cuadro 7). Llama la atención el deterioro educativo en el quintil más pobre en Argentina, que en vez de exhibir mejoras experimentó un leve retroceso. Esto estaría reflejando no sólo una creciente segmentación de la estructura social, sino también el estancamiento de las oportunidades de educación para los sectores más pobres.

Si bien en términos generales las tendencias en la región muestran un mayor acceso de los sectores pobres a la educación primaria, las disparidades se han mantenido - o agudizado - precisamente en aquellos niveles que resultan clave para la movilidad social. Las credenciales educativas han tenido un papel cada vez más decisivo en las posibilidades de acceder a los "buenos" empleos, día a día más escasos. El incremento de los niveles educativos de la población activa no sólo se ha traducido en una devaluación progresiva de la educación, sino en la creciente exclusión de los sectores con menor nivel educativo, cuyas oportunidades de empleo han disminuido fuertemente. Junto con elevarse el nivel educativo de la población, aumentaron los años de estudio mínimos requeridos para obtener empleos con ingresos por encima de los umbrales de pobreza. Si bien tener educación secundaria completa - o el equivalente a 12 años de educación- constituye una plataforma mínima necesaria, esta se hace cada vez más insuficiente por la importancia cada vez mayor que se asigna a la calidad de la educación recibida: los años de escolaridad ya no bastan como pasaporte para ingresar a los modernos puestos de trabajo: la "contraseña" tiende a ser el origen de la credencial educativa y el capital social familiar (Filmus y Miranda, 1999). ${ }^{27}$

Es precisamente en los niveles secundario y terciario donde las brechas son mayores. La ampliación de la cobertura educativa no ha disminuido las distancias entre los jóvenes procedentes de distintos estratos sociales. A partir de los 13 años de edad comienzan a ensancharse las diferencias de oportunidades educativas (cuadro 8). Al respecto llama la atención que en México el porcentaje que iba a la escuela de los jóvenes entre 13 y 19 años pertenecientes a los dos deciles más pobres haya permanecido casi estancado durante

${ }^{27}$ En el período 1999-2003 sólo 6,4\% de los jefes de hogares pobres en México y 17,8\% en Argentina habían superado los doce años de educación. En más de la mitad de los hogares pobres mexicanos el jefe tiene menos de seis años de estudio (CEPAL, 2004a). el período 1992-2002 (pasó de 55,6\% a 57,6\%), mientras que en los dos deciles más ricos subió de $80,7 \%$ a 92,8\%. Tanto en Argentina como en México, a pesar de las mejoras registradas en la década de 1990, entre los jóvenes de 20 a 24 años la brecha se amplía de manera dramática: en 2002 la asistencia escolar del $20 \%$ más rico triplicaba a la del $20 \%$ más pobre.

Según datos del 2000, entre los jóvenes de 20 a 24 años que habitan en zonas urbanas - hayan superado o no el nivel educativo de sus padres - hay un $38 \%$ en Argentina y un 46\% en México que no logran acceder al capital educativo básico ${ }^{28}$ necesario para aspirar a la obtención de un trabajo relativamente bien remunerado (CEPAL, 2004b). Este indicador ilustra las profundas desventajas iniciales que caracteriza el acceso al mercado laboral de los jóvenes provenientes de hogares de bajos ingresos y permiten anticipar su entrampamiento en inferiores oportunidades durante el curso de su vida, y la reproducción intergeneracional de esta situación.

La persistencia del nexo entre el acceso a la educación y el estrato social de origen indica que, en gran medida, las oportunidades de bienestar de quienes son jóvenes hoy ya quedaron plasmadas por el patrón de desigualdades prevaleciente en la generación anterior. Esto se traduce en una estructura social rígida y con escasa movilidad social (CEPAL, 2004b, p. 192).

\section{b) El debilitamiento del trabajo como canal de movilidad social}

Respecto a las oportunidades de movilidad ocupacional, algunos estudios recientes en México y Argentina muestran las escasas oportunidades de mejoramiento de quienes ingresan a las ocupaciones menos calificadas, así como su entrampamiento en las posiciones más precarias.

En su análisis de la movilidad social intergeneracional en áreas urbanas de México, Cortés y Escobar Latapí (2005) señalan que, en comparación con la etapa de industrialización sustitutiva de importaciones (antes de 1982), durante el período de reestructuración económica (1988-1994) disminuyeron las posibilidades de movilidad social en todos los estratos. Sin embargo, el efecto fue mucho más marcado en las clases de menores ingresos: trabajadores no calificados de la industria, trabajadores informales de los servicios, ejidatarios, pequeños propietarios rurales y jornaleros. Los autores observan que bajo el nuevo modelo

\footnotetext{
${ }^{28}$ Haber completado como mínimo doce años de educación.
} 
Argentina y México: Asistencia escolar en zonas urbanas, según quintil de ingreso per cápita del hogar y grupo de edad, 1990-2002

(Como porcentaje de la población de la misma edad)

\begin{tabular}{|c|c|c|c|c|c|c|c|c|c|}
\hline & \multicolumn{3}{|c|}{7 a 12 años } & \multicolumn{3}{|c|}{13 a 19 años } & \multicolumn{3}{|c|}{20 a 24 años } \\
\hline & Total & $\begin{array}{c}20 \% \\
\text { más pobre }\end{array}$ & $\begin{array}{c}20 \% \\
\text { más rico }\end{array}$ & Total & $\begin{array}{c}20 \% \\
\text { más pobre }\end{array}$ & $\begin{array}{c}20 \% \\
\text { más rico }\end{array}$ & Total & $\begin{array}{c}20 \% \\
\text { más pobre }\end{array}$ & $\begin{array}{c}20 \% \\
\text { más rico }\end{array}$ \\
\hline \multicolumn{10}{|c|}{ Argentina } \\
\hline 1990 & 98,4 & 97,9 & 100 & 68,8 & 62,6 & 79,3 & 23,6 & 12,4 & 39,8 \\
\hline 2002 & 99,4 & 99,1 & 100 & 83,2 & 76,3 & 96,4 & 40,6 & 21,7 & 61,6 \\
\hline \multicolumn{10}{|c|}{ México } \\
\hline 1992 & 97,4 & 95,8 & 99,5 & 62,7 & 55,6 & 80,7 & 23,9 & 7,1 & 47,3 \\
\hline 2002 & 98,1 & 96,3 & 99,6 & $68 ., 9$ & 57,6 & 92,8 & 30,7 & 16,4 & 55,1 \\
\hline
\end{tabular}

Fuente: CEPAL (2004a).

económico crece la desigualdad de oportunidades existente entre las clases más bajas y los originarios de la clase más alta — profesionales, funcionarios y empleadores de más de cinco trabajadores. Así, junto con intensificarse la desigualdad, el sistema de movilidad ocupacional se torna más rígido, y la ocupación del padre se vuelve un predictor más robusto del destino ocupacional (Cortés y Escobar Latapí, 2005).

En cuanto a Argentina, el trabajo de Kessler y Espinoza (2003) destaca dos elementos de particular importancia en los patrones emergentes de la movilidad social durante el decenio de 1990. En primer lugar, como en México, hay un bloqueo de las oportunidades de movilidad ocupacional ascendente entre los segmentos con mayores desventajas. A esto se agre-

\section{V}

\section{Conclusiones}

El análisis que se ha efectuado permite conocer mejor las formas que asume la relación entre la distribución del ingreso y los procesos de exclusión social en América Latina. La alta desigualdad en la distribución de oportunidades educativas y ocupacionales $-\mathrm{y}$, por lo tanto, de la protección social- revelan con crudeza que los niveles de ingreso son factores clave del acceso a los servicios sociales y - de un modo cada vez más marcado- de la calidad de los servicios a los que se accede. Esto genera una polarización y segmentación crecientes entre ciudadanos de primera y de segunda clase. El hogar de origen constituye un predictor gan transformaciones en la estructura ocupacional: un aumento relativo de la disponibilidad de puestos de trabajo que por sus exigencias de calificación corresponden a sectores medios, y a la vez una paulatina disminución de puestos correspondientes a sectores populares. Un segundo elemento es la necesidad de redefinir el significado de la movilidad social en el actual escenario económico. Al analizar las trayectorias de aquellos trabajadores que habrían exhibido una movilidad ocupacional ascendente en el período reciente, los autores destacan el desenganche entre el ascenso en la escala de prestigio ocupacional y las recompensas sociales anteriormente asociadas a esas posiciones, lo que estaría dando lugar a procesos de "movilidad espuria". ${ }^{29}$ cada vez más fuerte del lugar que se ocupará en la estructura social. Las ventajas o desventajas iniciales no sólo se mantienen - y profundizan - en el curso

\footnotetext{
${ }^{29}$ Se trastoca la relación funcional entre educación, ocupación e ingresos y la influencia de un factor sobre otros: la educación no contribuye necesariamente a la obtención de mejores empleos y, a su vez, estos no implican necesariamente la obtención de mayores ingresos. En un contexto de deterioro generalizado de las condiciones de trabajo, es muy probable que el acceso a ocupaciones tradicionalmente clasificadas como altas en la estructura ocupacional correspondan a puestos de peor calidad que en el pasado (Kesler y Espinoza, 2003).
} 
de la vida, sino que tienden a reproducirse entre generaciones.

Es precisamente el entrampamiento en circuitos de privación —en términos de educación, empleo, ingreso, vivienda, redes sociales- o, dicho de otro modo, la dificultad creciente que enfrentan los sectores más desfavorecidos para escapar de esos circuitos, lo que pone de manifiesto con más claridad las tendencias excluyentes del modelo neoliberal por el que han transitado las sociedades latinoamericanas - con diferentes ritmos e intensidades-durante las últimas dos décadas. Se trata no sólo de sociedades más desiguales y segmentadas, sino de estructuras sociales más rígidas en las cuales aparecen debilitados los anteriores canales y expectativas de movilidad social.

El potencial integrador alcanzado durante la etapa de industrialización sustitutiva de importaciones permitió alimentar las esperanzas de amplios sectores de la población de que "trabajando largo y duro" se podía mejorar la propia condición, poseer una casa, acceder a mayores oportunidades educativas para los hijos, construir un proyecto de vida, en síntesis, tener un "futuro mejor". Este optimismo comenzó a menguar de manera progresiva a partir del decenio de 1980, mientras que el de 1990 significó un quiebre definitivo con el "pasado". Los efectos demoledores de la utopía del mercado autorregulado sobre el tejido social (Polanyi, 1957) se dejaron sentir con fuerza tras el desmantelamiento de los anteriores mecanismos de protección social y la ausencia de políticas para evitar o paliar los costos sociales de las políticas de ajuste y los procesos de reestructuración económica.

La asociación entre la inestabilidad laboral, la pobreza y la desprotección social durante el período analizado se ha manifestado de manera diferente en México y en Argentina. En México, los bajos ingresos y la alta precariedad del empleo ponen en duda la eficacia de incrementar el número de perceptores de ingresos del hogar como mecanismo de protección frente a la pobreza. En otros términos, esa mayor densidad ocupacional por sí sola no basta para hacer que el hogar sea menos vulnerable a la pobreza; lo que hace la diferencia es la calidad de la inserción laboral, que se encuentra profundamente estratificada. En Argentina, el marcado deterioro del empleo fue acompañado por altos niveles de desempleo, los cuales se extendieron al conjunto de la población ocupada, pero afectaron con mayor intensidad a los sectores más desprotegidos por su precaria inserción laboral y bajos niveles educativos. Dada además la persistencia de desempleo alto - a pesar de la marcada disminución experimentada a partir de 2002—, podríamos estar asistiendo a una creciente incidencia de la pobreza en la población ocupada argentina, lo que estaría indicando, como en el caso de México, un progresivo debilitamiento del empleo como mecanismo para escapar de situaciones de pobreza.

El empleo, como los análisis de Argentina y México demuestran, no sólo es un bien cada vez más escaso, sino de muy baja calidad. El acceso a mejores oportunidades ocupacionales está fuertemente determinado por la posesión de habilidades y destrezas cognitivas a las cuales amplios sectores no tienen acceso. En estas condiciones emergen, se consolidan y se profundizan patrones de integración y pertenencia social altamente segmentados y polarizados. Tal multiplicación de situaciones de desventaja difícilmente puede ser abordada con enfoques y políticas que reducen el problema social a los sectores de extrema pobreza y de esta manera contribuyen a profundizar el dualismo y la segmentación social y a extender la desprotección a todos aquellos sectores que no forman parte de la población objetivo ni tienen posibilidades de acceder a los sistemas de protección provistos por el mercado.

Como señala Esping-Andersen (2002), el problema clave que debe resolverse para garantizar el bienestar de la población no puede ser solo el de aquellos cuyos ingresos caen bajo la línea de pobreza y/o que viven en condiciones precarias en un momento dado. Lo fundamental es identificar a los grupos con mayores probabilidades de permanecer persistentemente en empleos de bajos ingresos y en condiciones de vida precarias. Por lo tanto, se requiere un enfoque integral y dinámico tanto para encarar el problema como para formular políticas públicas que contribuyan a anticipar y evitar situaciones de desventaja antes de que estas se tornen irreversibles.

Los dilemas y desafíos que plantea el tránsito hacia sociedades más equitativas, solidarias e incluyentes y la necesidad de repensar los referentes mismos de la protección social exigen abordajes más complejos y dinámicos, tanto para comprender mejor las formas que asume la cuestión social en el nuevo escenario como para formular y aplicar políticas públicas en este campo que puedan dejar atrás el carácter fragmentario y desarticulado y los efectos muchas veces contrapuestos de políticas actuales. 
Altimir, O. y L. Beccaria (1999): El mercado de trabajo bajo el nuevo régimen económico en Argentina, serie Reformas económicas, N 28, LC/L.1217-P, Santiago de Chile, Comisión Económica para América Latina y el Caribe (CEPAL).

Banco Mundial (2003): Desigualdad en América Latina y el Caribe: ¿ruptura con la historia?, Washington, D.C.

Barry, B. (1998): Social Exclusion, Social Isolation and the Distribution of Income, CASE paper, $\mathrm{N}^{\circ} 12$, Londres, Centre for the Analysis of Social Exclusion, London School of Economics.

Bayón, M.C. (2002): Coping with Job Insecurity: The Experience of Unemployment in Contemporary Argentina, tesis de doctorado, Austin, Universidad de Texas en Austin.

Bayón, M.C., B. Roberts y G. Saraví (1998): Ciudadanía social y sector informal en América Latina, Perfiles latinoamericanos, $\mathrm{N}^{\mathrm{o}}$ 13, México, Facultad Latinoamericana de Ciencias Sociales (FLACSO), diciembre.

Beccaria, L., O. Altimir y M. González Rozada (2003): Estudio sobre empleo. Componente A: Economía laboral y políticas de empleo, Buenos Aires, Oficina de la CEPAL en Buenos Aires, marzo.

Bustelo, E. (1992): La producción del estado de malestar. Ajuste y política social en América Latina, en A. Minujin (comp.), Cuesta abajo. Los nuevos pobres: efectos de la crisis en la sociedad argentina, Buenos Aires, Fondo de las Naciones Unidas para la Infancia (UNICEF)/Losada.

Canales, A. (2002): Migración y trabajo en la era de la globalización: el caso de la migración México-Estados Unidos en la década de 1990, Papeles de población, año 8, No 33, México, D.F., Universidad Autónoma del Estado de México, julio-septiembre.

CEPAL (Comisión Económica para América Latina y el Caribe) (1989): Transformación ocupacional y crisis social en América Latina, Libros de la CEPAL, $N^{\circ}$ 22, LC/G. 1558-P, Santiago de Chile. Publicación de las Naciones Unidas, $\mathrm{N}^{\circ}$ de venta: S.90.II.G.3.

(1990): Anuario estadístico de América Latina y el Caribe, 1989, LC/G.1606-P, Santiago de Chile. Publicación de las Naciones Unidas, $\mathrm{N}^{\circ}$ de venta: 90.II.G.1.

(2003): Panorama social de América Latina, 2002-2003, LC/G.2209-P, Santiago de Chile, agosto. Publicación de las Naciones Unidas, $\mathrm{N}^{\circ}$ de venta: S.03.II.G.185.

(2004a): Panorama social de América Latina, 2004, LC/ L.2220-P, Santiago de Chile, noviembre. Publicación de las Naciones Unidas, $\mathrm{N}^{\circ}$ de venta: S.04.II.G.148.

(2004b): Una década de desarrollo social en América Latina, 1990-1999, LC/G.2212-P, Santiago de Chile. Publicación de las Naciones Unidas, $\mathrm{N}^{\mathrm{o}}$ de venta: S.03.II.G.143.

(2004c): Anuario estadístico de América Latina y el Caribe 2003, LC/G.2224-P, Santiago de Chile, mayo. Publicación de las Naciones Unidas, $\mathrm{N}^{\mathrm{o}}$ de venta: E/S.04.II.G.1.

(2004d): Balance preliminar de las economías de América Latina y el Caribe, 2004, LC/G.2265-P, Santiago de Chile diciembre. Publicación de las Naciones Unidas, $\mathrm{N}^{\mathbf{0}}$ de venta: S.04.II.G.147.

(varios años): Panorama social de América Latina, Santiago de Chile.

COPLAMAR (Coordinación General del Plan Nacional de Zonas Deprimidas y Grupos Marginados) (1985): Las necesidades esenciales en México. Situación actual y perspectivas al año 2000, México, D.F., Siglo XXI.

Cortés, F. (2000): La distribución del ingreso en épocas de estabilización y reforma económica, México, D.F., Centro de Investigaciones y Estudios Superiores de Antropología Social (CIESAS)/Miguel Angel Porrúa.
Cortés, F. y A. Escobar Latapí (2005): Movilidad social intergeneracional en el México urbano, Revista de la CEPAL, $\mathrm{N}^{\circ}$ 85, LC/G.2266-P, Santiago de Chile, abril.

Damill, M., R. Frenkel y R. Maurizio (2002): Argentina: una década de convertibilidad. Un análisis del crecimiento, el empleo y la distribución del ingreso, Santiago de Chile, Organización Internacional del Trabajo (OIT).

Esping-Andersen, G. (2002): Towards a good society, once again?, en G. Esping-Andersen, D. Gallie y otros (comps.), Why We Need a New Welfare State?, Nueva York, Oxford University Press.

Esping-Andersen, G. y M. Regini (2000): Why Deregulate Labor Markets?, Oxford, Oxford University Press.

Estrada Iguiñiz, M. (1996): Después del despido. Desocupación y familia obrera, México D.F., Centro de Investigaciones y Estudios Superiores de Antropología Social (CIESAS)/Ediciones de la Casa Chata.

Faria, V. (1995): Social Exclusion and Latin American analyses of poverty and deprivation, en G. Rodgers, C. Gore y J. Figuereido (comps.), Social Exclusion: Rhetoric, Reality, Responses, Ginebra, Organización Internacional del Trabajo (OIT).

Filgueira, F. (1998): El nuevo modelo de prestaciones sociales en América Latina. Eficiencia, residualismo y ciudadanía estratificada, en B. Roberts (comp.), Ciudadanía y política social, San José, Facultad Latinoamericana de Ciencias Sociales (FLACSO).

Filmus, D. y A. Miranda (1999): América Latina y Argentina en los noventa: más educación, menos trabajo = más desigualdad, en D. Filmus (comp.), Los noventa. Política, sociedad y cultura en América Latina y Argentina de fin de siglo, Buenos Aires, FLACSO/EUDEBA.

Frenkel, R. y J. Ros (2004): Unemployment, Macroeconomic Policy and Labor Market Flexibility: Argentina and Mexico in the 1990s, documento presentado al Seminario sobre gestión, volatilidad, liberalización financiera y crecimiento en economías emergentes (Santiago de Chile, 24 y 25 de abril).

Gallie, D. y S. Paugam (comps.) (2000): Welfare Regimes and the Experience of Unemployment in Europe, Nueva York, Oxford University Press.

(2002): Social Precarity and Social Integration, Bruselas, Eurobarómetro.

Gallie, D., S. Jacobs y S. Paugam (2000): Poverty and financial hardship among the unemployed, en D. Gallie y S. Paugam (comps.), Welfare Regimes and the Experience of Unemployment in Europe, Nueva York, Oxford University Press.

Gasparini, L. (2004): América Latina: estudio de la protección social y el empleo sobre la base de encuesta de hogares, en F. Bertranou (comp.), Protección social y mercado laboral, Santiago de Chile, Organización Internacional del Trabajo (OIT).

Gurrieri, A. y P. Sainz (2003): Empleo y movilidad estructural. Trayectoria de un tema prebischiano, Revista de la CEPAL, No 80, LC/G.2204-P, Santiago de Chile, agosto.

Hernández Laos, E. (2003): Distribución del ingreso y pobreza, en E. de la Garza y C. Salas (coords.), La situación del trabajo en México, 2003, México, D.F., Instituto de Estudios del Trabajo (IET).

Heymann, D. (2000): Politicas de reforma y comportamiento macroeconómico: la Argentina en los noventa, serie Reformas económicas, $\mathrm{N}^{\circ}$ 61, LC/L.1357, Santiago de Chile, Comisión Económica para América Latina y el Caribe (CEPAL)

INEGI (Instituto Nacional de Estadística, Geografía e Informática) (1985): Estadísticas históricas de México, México, D.F. 
(2001): Encuesta Nacional de Empleo, México, D.F. (2004): Encuesta Nacional de Empleo, México, D.F. (2005): Encuesta Nacional de Ocupación y Empleo, México, D.F.

Katz, J., R. Bisang y G. Burachik (comps.) (1995): Hacia un nuevo modelo de organización industrial. El sector manufacturero argentino en los años 90, Buenos Aires, Alianza Editorial.

Kessler, G. y V. Espinoza (2003): Movilidad social y trayectorias ocupacionales en Argentina: rupturas y algunas paradojas del caso de Buenos Aires, serie Políticas sociales, $\mathrm{N}^{\circ} 66, \mathrm{LC} /$ L.1895-P, Santiago de Chile, Comisión Económica para América Latina y el Caribe (CEPAL). Publicación de las Naciones Unidas, $\mathrm{N}^{\circ}$ de venta: S.03.II.G.55.

Klein, E. y V. Tokman (2000): La estratificación social bajo tensión en la era de la globalización, Revista de la CEPAL, $\mathrm{N}^{\circ} 72$, LC/G.2120-P, diciembre.

López, G. (1999): Evolución reciente del empleo en México, serie Reformas económicas, Nº 29, LC/L.1218-P, Santiago de Chile, Comisión Económica para América Latina y el Caribe (CEPAL).

Marshall, A. (1978): El mercado de trabajo en el capitalismo pe riférico. El caso de Argentina, Buenos Aires, Programa de Investigaciones Sociales sobre Población en América Latina (PISPAL)/ Consejo Latinoamericano de Ciencias Sociales (CLACSO).

(1998): State intervention, the labor market and inequality in Argentina, en A. Berry (comp.), Poverty, Economic Reform, and Income Distribution in Latin America, Boulder, Colorado, Lynne Rienner Publishers.

Marshall, T.H. (1992): Citizenship and social class, en T.H. Marshal y T. Bottomore (comps.), Citizenship and Social Class, Londres, Pluto Press. Publicado originalmente en 1950.

Moreno Brid, J.C. y J. Ros (2004): México: las reformas del mercado desde una perspectiva histórica, Revista de la CEPAL, $\mathrm{N}^{\circ}$ 84, LC/G.2258-P, Santiago de Chile, diciembre.

OIT (Oficina Internacional del Trabajo) (2003): Panorama laboral 2003. América Latina y el Caribe, Lima, Organización Internacional del Trabajo (OIT).

(2004): Panorama laboral 2004. América Latina y el Caribe, Lima, Organización Internacional del Trabajo (OIT).

OIT/MECON (Organización Internacional del Trabajo/Ministerio de Economía) (2005): Protección social en Argentina: cobertura, financiamiento y desempeño, 1990-2003, Buenos Aires.

Paugam, S. (1995): The spiral of precariousness: a multidimensional approach to the process of social disqualification in France, en G. Room (comp.), Beyond the Threshold: The Measurement and Analysis of Social Exclusion, Bristol, The Policy Press.

Pérez Sainz, J.P. (2003): Exclusión laboral en América Latina: viejas y nuevas tendencias, en Sociología del Trabajo. Nueva épo$\mathrm{ca}, \mathrm{N}^{\circ}$ 47, Madrid, Siglo XXI Editores.

PNUD (Programa de las Naciones Unidas para el Desarrollo) (2003): Informe sobre desarrollo humano 2003, Nueva York, Oxford University Press.

Polanyi, K. (1957): The Great Transformation. The Political and Economic Origins of Our Time, Boston, Beacon Press.

Portes, A. y K. Hoffman (2003): Latin American class structures: their composition and change during the neoliberal era, Latin American Research Review, vol. 38, № 1, Pittsburgh, The Latin American Studies Association.

PREALC (Programa Regional del Empleo para América Latina y el Caribe) (1982): Mercado de trabajo en cifras, 1950-1980, Santiago de Chile, Organización Internacional del Trabajo (OIT).

Reimers, F. (2000): Educational opportunity and policy in Latin America, en F. Reimers (comp.), Unequal Schools, Unequal Chances: The Challenges of Equal Opportunity in the Americas, Londres, Harvard University Press.

Rendón, T. y C. Salas (2000): La evolución del empleo, en G. Bensusán y T. Rendón (coords.), Trabajo y trabajadores en el México contemporáneo, México, D.F., Miguel Angel Porrúa.

Roberts, B. (2004): From marginality to social exclusion: from laissez faire to pervasive engagement, Latin American Research Review, vol. 39, No 1, Pittsburgh, The Latin American Studies Association.

Salas, C. y E. Zepeda (2003): Empleo y salarios en el México contemporáneo, en E. de la Garza y C. Salas (coords.), La situación del trabajo en México, 2003, México, D.F., Instituto de Estudios del Trabajo (IET).

Sen, A. (2000): Social Exclusion: Concept, Application, and Scrutiny, Social Development Papers, $\mathrm{N}^{\circ} 1$, Manila, Banco Asiático de Desarrollo.

Selby, H., A. Murphy y S. Lorenzen (1994): La familia en México urbano, México, D.F., Conaculta.

Stallings, B. y J. Weller (2001): Job Creation in Latin America in the 1990s: The Foundation for Social Policy, serie Macroeconomía del desarrollo, No 5, LC/L.1572-P, Santiago de Chile, Comisión Económica para América Latina y el Caribe (CEPAL). Publicación de las Naciones Unidas, $\mathrm{N}^{\circ}$ de venta: E.01.II.G.115

Torrado, S. (1992): Estructura social de la Argentina: 1945-1983, Buenos Aires, Ediciones de la Flor. 